\title{
Estimated glomerular filtration rate, albuminuria and mortality in type 2 diabetes: the Casale Monferrato study
}

\author{
G. Bruno • F. Merletti • G. Bargero • G. Novelli • \\ D. Melis • A. Soddu • M. Perotto • G. Pagano • \\ P. Cavallo-Perin
}

Received: 20 November 2006 / Accepted: 20 December 2006 / Published online: 2 March 2007

(C) Springer-Verlag 2007

\begin{abstract}
Aims/hypothesis Estimated glomerular filtration rate (eGFR) predicts mortality in non-diabetic populations, but its role in people with type 2 diabetes is unknown. We assessed to what extent a reduction in eGFR in people with type 2 diabetes predicts 11-year all-cause and cardiovascular mortality, independently of AER and other cardiovascular risk factors. Materials and methods The study population was the population-based cohort ( $\mathrm{n}=1,538$; median age 68.9 years) of the Casale Monferrato Study. GFR was estimated by the abbreviated Modification of Diet in Renal Disease Study equation.

Results At baseline, the prevalence of chronic kidney disease (eGFR $<60 \mathrm{ml} \mathrm{min} \min ^{-1} 1.73 \mathrm{~m}^{-2}$ ) was $34.3 \%$ (95\% CI 33.0-36.8). There were 670 deaths in 10,708 person-years of observation. Hazard ratios of 1.23 (95\% CI $1.03-1.47)$ for all-cause mortality and 1.18 (95\% CI 0.92 1.52) for cardiovascular mortality were observed after adjusting for cardiovascular risk factors and AER. When five levels of eGFR were analysed we found that most risk was conferred by eGFR $15-29 \mathrm{ml} \mathrm{min}^{-1} 1.73 \mathrm{~m}^{-2}$, whereas
\end{abstract}

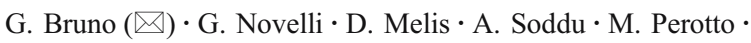

G. Pagano $\cdot$ P. Cavallo-Perin

Department of Internal Medicine,

University of Torino,

corso Dogliotti 14,

I-10126 Torino, Italy

e-mail: graziella.bruno@unito.it

F. Merletti

Unit of Cancer Epidemiology, CERMS, University of Torino,

Torino, Italy

G. Bargero

Santo Spirito Hospital, Casale Monferrato,

Alessandria, Italy no increased risk was evident in people with eGFR values between 30 and $59 \mathrm{ml} \mathrm{min}^{-1} 1.73 \mathrm{~m}^{-2}$. In an analysis stratified by AER categories, a significant increasing trend in risk with decreasing eGFR was evident only in people with macroalbuminuria.

Conclusions/interpretation Our study suggests that in type 2 diabetes macroalbuminuria is the main predictor of mortality, independently of both eGFR and cardiovascular risk factors, whereas eGFR provides no further information in normoalbuminuric people.

Keywords Cohort · Diabetic nephropathy · Epidemiology . Mortality $\cdot$ Survey
Abbreviations
apo apolipoprotein
eGFR estimated glomerular filtration rate
HR hazard rate ratio
MDRD Modification of Diet in Renal Disease (study)

\section{Introduction}

Cardiovascular risk is higher among people with chronic kidney disease than among those with normal renal function, even after adjustment for traditional risk factors [1-7]. This association is probably due to systemic atherosclerosis and reduced renal function acting as a marker rather than a determinant of vascular dysfunction. Early identification of people with reduced renal function would make it possible to target treatment and to prevent progression to end-stage renal disease and cardiovascular complications. Compared with non-diabetic people, those with type 2 diabetes are at increased risk of both renal and 
cardiovascular diseases. Thus, the American Diabetes Association has recommended that serum creatinine should be measured at least annually for the estimation of GFR, regardless of the degree of albuminuria, to identify the stage of chronic kidney disease [8]. Whereas the time-consuming and expensive direct measurement of GFR is difficult to perform, the estimated GFR (eGFR) using the abbreviated equation from the Modification of Diet in Renal Disease (MDRD) study has been suggested as the best validated means for transforming serum creatinine measurements into GFR in adults, using age, sex and ethnicity as surrogates for muscle mass $[9,10]$. At present no prospective populationbased study has assessed the value of eGFR for predicting survival rates in people with type 2 diabetes. Moreover, it is presently unknown whether knowledge of eGFR provides further information on cardiovascular risk in addition to that provided by the albumin excretion rate (AER).

The Casale Monferrato Study is an ongoing Italian population-based study, which in 1988 identified a cohort of people with diagnosed type 2 diabetes and prospectively assesses the incidence of diabetic nephropathy and the risk of mortality [11-14]. The aims of this study were to assess in an 11-year follow-up the ability of eGFR to predict allcause and cardiovascular mortality, independently of conventional risk factors and AER.

\section{Subjects and methods}

The study comprised 1,565 persons with known type 2 diabetes who were resident in 1988 in the town of Casale Monferrato in north-west Italy (93,477 inhabitants). These individuals were invited to undergo a baseline examination in 1991-1992 to assess the prevalence of micro- and macroalbuminuria and cardiovascular risk factors and were followed up until 31 December 2001 [11-14]. Participants were identified from diabetes clinics, general practitioners, hospital discharge records, prescriptions and records of sales of reagent strips and syringes. A high degree of ascertainment was achieved (80\%) [15]. Surveys conducted in Italy showed that the participants were representative of patients with diabetes in the country with regard to age, sex, duration of diabetes, BMI and type of glucose-lowering treatment [16].

As described in detail elsewhere, all patients were interviewed and examined by trained investigators at baseline [11]. All individuals gave informed consent and the study was carried out in accordance with the Declaration of Helsinki. Hypertension was defined as systolic blood pressure $\geq 140 \mathrm{mmHg}$, or diastolic blood pressure $\geq 90 \mathrm{mmHg}$, or treatment with antihypertensive drugs. All laboratory determinations were centralised. Venous blood samples were collected after fasting for determination of creatinine, triacylglycerol, total cholesterol, HDL-cholesterol (enzymatic colorimetric method after precipitation with $\mathrm{Mn}^{2+}$ ), apolipoprotein (apo) $\mathrm{A} 1$, apoB (turbidimetric method, BM/Hitachi 717; BBR, Tokyo, Japan) and $\mathrm{HbA}_{1 \mathrm{c}}$ (HPLC; Daiichi, Menarini, Japan; laboratory reference range $3.8-5.5 \%$ ). For the purpose of this study, analysis was performed on 1,539 subjects who had baseline serum creatinine measurements (Jaffe method). We estimated GFR by using the four-component abbreviated equation from the MDRD study (all patients were Europids): $\mathrm{eGFR}=186 \times$ $(\text { serum creatinine }[\mathrm{mg} / \mathrm{dl}])^{1.154} \times \mathrm{age}^{0.203}(\times 0.742$ if female $)$ [9]. The distribution of eGFR was divided into five categories: $15-29,30-44,45-59,60-89$ and $\geq 90 \mathrm{ml} \mathrm{min}^{-1}$ $1.73 \mathrm{~m}^{-2}$. People with eGFR $<60 \mathrm{ml} \mathrm{min}^{-1} 1.73 \mathrm{~m}^{-2}$ were defined as having chronic kidney disease.

LDL-cholesterol was calculated from Friedewald's formula for all except 44 people in the cohort who had triacylglycerol values $>4.48 \mathrm{mmol} / \mathrm{l}(400 \mathrm{mg} / \mathrm{dl})$. AER was calculated on the basis of the urinary albumin concentration measured in a single, timed, overnight urine sample collected by the nephelometric method (Behring Nephelometer Analyzer; Behring Institute, Marburg, Germany), after exclusion of urinary tract infection, congestive heart failure and other known causes of non-diabetic renal disease. Smoking was classified into: never; ex-smoker if the patient had stopped smoking at least 1 month before the visit; and smoker. For all patients enrolled, the date of diagnosis was recorded.

During the follow-up period (1991-2001) the participants were examined regularly during routine clinical practice, three or four times per year, either at the diabetes clinic or by general practitioners. The relevant time scale for the analysis was time since diagnosis of diabetes to death or to 31 December 2001, whichever came first, with left truncation for the period of time from onset of diabetes to 1991 . Information on deaths was obtained from the demographic files of towns of residence and hospital discharge and autopsy records. Only one patient was lost to follow-up. The underlying causes of death were derived and coded by two of the authors (G. Bruno and F. Merletti) according to the ninth revision of the International Classification of Diseases (ICD). Mortality rates were calculated by dividing the number of deaths that occurred during the study period by the number of person-years of observation.

All continuous variables were categorised into quartiles of their distribution, except for age, which was categorised into 5 -year age groups $(<60,60-64,65-69,70-74,75-79,>79)$. The excess risk of death from cardiovascular disease (ICD9 codes 390-459) and from all causes was expressed as hazard rate ratios (HRs). Variable-adjusted HRs were calculated by multivariate Cox proportional hazards modelling. Given the time scale, all the models were also adjusted for known duration of diabetes. We tested for linear trends across categorical variables by entering a single ordinal term 
into the Cox regression model. The proportional hazard assumptions of explanatory variables were assessed on the basis of Schoenfeld residuals. We tested for the effect of age and AER on eGFR by including interaction terms in the models. The likelihood ratio test was used to assess the significance of variables. The $p$ value was two-sided; a $p$ value $<0.05$ was considered to indicate statistical significance. All analyses were performed with Stata (release 8.0; Stata Corporation, College Station, TX, USA).

\section{Results}

The prevalence of chronic kidney disease (eGFR $<60 \mathrm{ml} \mathrm{min}^{-1}$ $\left.1.73 \mathrm{~m}^{-2}\right)$ was $34.3 \%(95 \%$ CI $33.0-36.8)$, and it was higher in women than in men $(45.8 \%, 95 \%$ CI $42.4-49.1$ vs $19.5 \%$, 95\% CI 16.5-22.7), even after age adjustment (odds ratio $3.10,95 \%$ CI 2.42-3.97). In normo-, micro- and macroalbuminuric people, the prevalence of chronic kidney disease was $29.4 \%$ (95\% CI $26.2-32.8), 35.8 \%$ (95\% CI 31.5-40.2) and $44.9 \%$ (95\% CI $38.8-51.1)$, respectively. Higher risk in micro- and macroalbuminuric people than in those with normoalbuminuria was confirmed after adjustment for age and sex: the odds ratio was $1.38(95 \%$ CI $1.05-1.81)$ and 2.04 (95\% CI 1.47-2.84), respectively.
The baseline features of the cohort by categories of eGFR are shown in Table 1. Persons in the lowest category of eGFR had the highest mean values of duration of diabetes, systolic and diastolic blood pressure, plasma triacylglycerol, apoB, fibrinogen and uric acid. The proportion of patients who had diabetic nephropathy also increased with decreasing eGFR; no normoalbuminuric person had eGFR $<30 \mathrm{ml} \mathrm{min}^{-1} 1.73 \mathrm{~m}^{-2}$.

During the 11-year follow-up, 670 deaths were observed in 10,708 person-years of observation. With regard to people with eGFR $\geq 60 \mathrm{ml} \mathrm{min}^{-1} 1.73 \mathrm{~m}^{-2}$, those with values $<60 \mathrm{ml}$ $\min ^{-1} 1.73 \mathrm{~m}^{-2}$ had a twofold higher risk of mortality, and an increasing trend across decreasing eGFR categories was also evident ( $p$ for trend $<0.00001$; Table 2 ). With regard to univariate analysis, adjustment for age markedly reduced the strength of this association. In Cox regression analysis

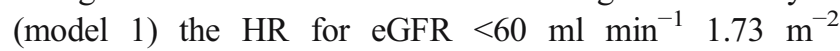
decreased from 2.16 to 1.39 for cardiovascular mortality and from 1.92 to 1.32 for all-cause mortality after adjustment for age and sex (Table 3). Similar results were obtained when quartiles of plasma creatinine were analysed.

In the fully adjusted model, we found that chronic kidney disease conferred an increased risk of all-cause mortality of $23 \%$ and of cardiovascular mortality of $18 \%$, independently of both cardiovascular risk factors and AER.

Table 1 Characteristics of the people with type 2 diabetes in the Casale Monferrato Study according to eGFR at baseline examination (1991-1992)

\begin{tabular}{|c|c|c|c|c|c|c|}
\hline & \multicolumn{5}{|c|}{ eGFR (ml min $\left.{ }^{-1} 1.73 \mathrm{~m}^{-2}\right)$} & \multirow[t]{2}{*}{$p$ value } \\
\hline & $\geq 90(n=113)$ & $60-89(n=898)$ & $45-59(n=400)$ & $30-44(n=106)$ & $15-29(n=21)$ & \\
\hline Age (years) & $59.5 \pm 10.5$ & $66.6 \pm 10.2$ & $73.5 \pm 8.7$ & $76.2 \pm 8.6$ & $75.4 \pm 8.5$ & $<0.0001$ \\
\hline Men $(\%)$ & $87(77.0 \%)$ & $451(50.2 \%)$ & $95(23.8 \%)$ & $26(24.5 \%)$ & $9(39.1 \%)$ & $<0.0001$ \\
\hline Duration of diabetes (years) & $10.0 \pm 7.0$ & $10.3 \pm 6.6$ & $11.4 \pm 7.0$ & $12.9 \pm 8.1$ & $14.2 \pm 8.8$ & $<0.0001$ \\
\hline BMI $\left(\mathrm{kg} / \mathrm{m}^{2}\right)$ & $27.5 \pm 4.4$ & $27.3 \pm 4.8$ & $27.2 \pm 4.5$ & $26.7 \pm 4.1$ & $27.2 \pm 3.9$ & 0.69 \\
\hline $\mathrm{HbA}_{1 \mathrm{c}}(\%)$ & $8.3 \pm 2.4$ & $8.0 \pm 2.3$ & $7.9 \pm 2.2$ & $8.3 \pm 2.2$ & $8.6 \pm 2.2$ & 0.23 \\
\hline Total cholesterol $(\mathrm{mmol} / \mathrm{l})$ & $5.70 \pm 1.33$ & $5.76 \pm 1.23$ & $5.92 \pm 1.26$ & $5.64 \pm 1.35$ & $5.48 \pm 1.45$ & 0.08 \\
\hline LDL-cholesterol (mmol/l) & $3.59 \pm 1.18$ & $3.58 \pm 1.06$ & $3.71 \pm 1.12$ & $3.37 \pm 1.08$ & $3.14 \pm 1.27$ & 0.02 \\
\hline HDL-cholesterol (mmol/l) & $1.47 \pm 0.44$ & $1.43 \pm 0.42$ & $1.41 \pm 0.41$ & $1.27 \pm 0.38$ & $1.07 \pm 0.32$ & $<0.0001$ \\
\hline Triacylglycerol $(\mathrm{mmol} / \mathrm{l})^{\mathrm{a}}$ & 1.32 & 1.47 & 1.61 & 1.90 & 2.34 & $<0.0001$ \\
\hline ApoA1 $(g / l)$ & $1.34 \pm 0.41$ & $1.35 \pm 0.34$ & $1.36 \pm 0.34$ & $1.27 \pm 0.32$ & $1.20 \pm 0.26$ & 0.05 \\
\hline ApoB (g/l) & $1.00 \pm 0.40$ & $1.02 \pm 0.37$ & $1.09 \pm 0.38$ & $1.04 \pm 0.37$ & $1.18 \pm 0.28$ & 0.002 \\
\hline ApoB/apoA1 & $0.86 \pm 0.10$ & $0.78 \pm 0.30$ & $0.83 \pm 0.32$ & $0.84 \pm 0.29$ & $1.00 \pm 0.25$ & 0.001 \\
\hline Fibrinogen $(\mathrm{g} / \mathrm{l})$ & $3.46 \pm 0.84$ & $3.56 \pm 0.91$ & $3.74 \pm 0.93$ & $3.85 \pm 0.88$ & $3.94 \pm 0.94$ & 0.0001 \\
\hline Uric acid (mmol/l) & $280 \pm 83$ & $309 \pm 95$ & $339 \pm 89$ & $393 \pm 107$ & $425 \pm 149$ & $<0.0001$ \\
\hline \multicolumn{7}{|l|}{ Blood pressure (mmHg) } \\
\hline Systolic & $145.3 \pm 18.6$ & $153.3 \pm 21.3$ & $157.5 \pm 21.6$ & $162.1 \pm 24.8$ & $156.8 \pm 23.3$ & $<0.0001$ \\
\hline Diastolic & $85.1 \pm 9.4$ & $87.3 \pm 10.4$ & $88.1 \pm 10.2$ & $88.6 \pm 11.1$ & $88.7 \pm 12.6$ & $<0.0001$ \\
\hline Hypertension (\%) & $80(70.8 \%)$ & $741(83.0 \%)$ & $352(89.1 \%)$ & $95(92.2 \%)$ & $20(90.9 \%)$ & $<0.0001$ \\
\hline CHD $(\%)$ & $22(23.7 \%)$ & $162(21.4 \%)$ & $94(28.8 \%)$ & $37(38.5 \%)$ & $6(27.3 \%)$ & 0.002 \\
\hline \multicolumn{7}{|l|}{$\operatorname{AER}(\mu \mathrm{g} / \mathrm{min})$} \\
\hline$<20(100 \%)$ & $60(8.0 \%)$ & $472(62.6 \%)$ & $194(27.7 \%)$ & $28(3.7 \%)$ & 0 & $<0.0001$ \\
\hline $20-200(100 \%)$ & $39(8.1 \%)$ & $270(56.1 \%)$ & $125(26.0 \%)$ & $38(7.9 \%)$ & $8(1.9 \%)$ & \\
\hline$>200(100 \%)$ & $12(4.6 \%)$ & $133(50.6 \%)$ & $67(25.5 \%)$ & $38(14.5 \%)$ & $13(4.9 \%)$ & \\
\hline
\end{tabular}

${ }^{\text {a }}$ Geometric mean 
Table 2 Mortality rates in people with type 2 diabetes in the Casale Monferrato Study according to eGFR and serum creatinine quartiles at baseline examination (1991-1992)

All-cause mortality

No. of Rate per $1000 \quad$ HR $(95 \%$ CI)

deaths person-years

$\begin{array}{rc}366 & 48.7 \\ 304 & 95.3 \\ & \\ 37 & 42.5 \\ 329 & 49.5 \\ 217 & 85.8 \\ 66 & 108.8 \\ 21 & 377.14\end{array}$

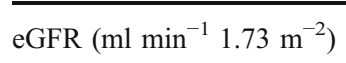

$\geq 60$ (with chronic kidney disease)

$<60$ (without chronic kidney disease)

Further classification

$60-89$

$45-59$

$30-44$

15-29

$p$ for trend

Serum creatinine $(\mu \mathrm{mol} / \mathrm{l})$

$<80$

$80-87$

$88-103$

$>103$

$p$ for trend
Cardiovascular mortality

No. of Rate per $1000 \quad$ HR $(95 \%$ CI $)$

deaths person-years

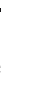

However, when five levels of eGFR were included in models rather than two levels, a tendency towards a Jshaped pattern of risk was evident. Indeed, compared with people with eGFR $\geq 90 \mathrm{ml} \mathrm{min}{ }^{-1} 1.73 \mathrm{~m}^{-2}$ (HR 1.0), HR was lower in those with eGFR $60-89 \mathrm{ml} \mathrm{min}^{-1} 1.73 \mathrm{~m}^{-2}$ (HR $0.73,95 \%$ CI $0.51-1.05$ ) and higher in those in the lowest category of eGFR for all-cause mortality (HR 2.36, 95\% CI 1.28-4.34). A similar pattern was seen for cardiovascular mortality: the HR was 0.65 (95\% CI $0.39-1.11)$ in the eGFR category $60-89 \mathrm{ml} \mathrm{min}^{-1} 1.73 \mathrm{~m}^{-2}$ and 2.03 (95\% CI $0.85-4.85)$ in the lowest eGFR category. The lowest level of eGFR included only 21 subjects; however, $100 \%$ of them died during follow-up, compared with $32.7 \%$ among those with eGFR $\geq 90 \mathrm{ml} \mathrm{min}^{-1} 1.73 \mathrm{~m}^{-2}$. In the intermediate eGFR categories, frequencies of death were $36.6,54.3$ and $62.3 \%$, respectively.

As the interaction term between age and eGFR was significant $(p<0.001)$, fully adjusted models were also performed separately in people aged $<70$ years and in those aged $\geq 70$ years at baseline. HRs of all-cause mortality in people with eGFR $<60 \mathrm{ml} \mathrm{min}{ }^{-1} 1.73 \mathrm{~m}^{-2}$ were 1.51 (95\% CI $1.07-2.13)$ aged $<70$ years and 1.09 $(95 \%$ CI $0.89-1.35)$ in those aged $\geq 70$ years; corresponding values for cardiovascular mortality were 1.46 (95\% CI 0.85-2.51) and 1.07 (95\% CI 0.80-1.42).

As the interaction term between AER and eGFR was significant ( $p=0.023$ ), we performed a stratified analysis by AER categories, adjusted for age and sex only, given the low numbers of events in each stratum (Table 4). This analysis showed increasing trend of HRs by decreasing eGFR values in macroalbuminuric people only.

\section{Discussion}

Our population-based study provides evidence that in persons with type 2 diabetes the most important predictor of all-cause and cardiovascular mortality is AER, whereas GFR estimated with the MDRD study formula has limited clinical usefulness, its predict ability being mainly due to the effects of age, sex and AER.

Our finding is original, no previous prospective study having examined the relationship between eGFR and mortality in a population-based cohort of people with type 2 diabetes. As people with diabetes have increased risk of cardiovascular disease, diabetologists are interested in the identification of factors allowing them to improve the prediction of the individual risk of their patients. Data derived from cohorts of non-diabetic people showing the relationship between reduced eGFR and increased cardiovascular events have suggested that a similar association could also apply to diabetic people [1-7]. Diabetes, however, is characterised by early abnormalities in renal permeability, leading at first to microalbuminuria, a marker of endothelial dysfunction, and then to overt diabetic nephropathy. Both phases, particularly the latter, are characterised not only by an increased risk of progression to end-stage renal disease, but mainly by a higher cardiovascular risk than in people with normoalbuminuria $[12,13,17,18]$. It is therefore relevant to assess whether eGFR predicts mortality and if this relation is modified by AER values. Two previous clinic-based studies have assessed the effect on survival of eGFR in diabetic people $[19,20]$. The study performed in the Veterans Affairs 
Table 3 Hazard ratios (HRs) for mortality in people with type 2 diabetes in the Casale Monferrato study

\begin{tabular}{|c|c|c|c|}
\hline & Model $1^{\mathrm{a}}$ & Model $2^{\mathrm{b}}$ & Model $3^{\mathrm{c}}$ \\
\hline \multicolumn{4}{|l|}{ All-cause mortality } \\
\hline \multicolumn{4}{|l|}{ eGFR $\left(\mathrm{ml} \mathrm{min}-1.73 \mathrm{~m}^{-2}\right)$} \\
\hline For every $\mathrm{ml} \mathrm{min}^{-1} 1.73 \mathrm{~m}^{-2}$ & $1.24(1.12-1.38)$ & $1.16(1.05-1.29)$ & $1.11(1.00-1.24)$ \\
\hline$\geq 60$ (with chronic kidney disease) & 1.00 & 1.00 & 1.00 \\
\hline$<60$ (without chronic kidney disease) & $1.32(1.11-1.56)$ & $1.24(1.05-1.47)$ & $1.23(1.03-1.47)$ \\
\hline \multicolumn{4}{|l|}{ Further classification } \\
\hline$\geq 90$ & 1.00 & 1.00 & 1.00 \\
\hline $60-89$ & $0.83(0.58-1.17)$ & $0.78(0.55-1.11)$ & $0.73(0.51-1.05)$ \\
\hline $45-59$ & $1.02(0.70-1.49)$ & $0.95(0.65-1.38)$ & $0.93(0.62-1.37)$ \\
\hline $30-44$ & $1.10(0.72-1.68)$ & $0.90(0.58-1.38)$ & $0.74(0.47-1.16)$ \\
\hline $15-29$ & $4.12(2.36-7.18)$ & $2.79(1.57-4.94)$ & $2.36(1.28-4.34)$ \\
\hline$p$ value for trend & $<0.0001$ & 0.005 & 0.056 \\
\hline \multicolumn{4}{|l|}{ AER } \\
\hline$<20 \mu \mathrm{g} / \mathrm{min}$ & 1.00 & 1.00 & 1.00 \\
\hline $20-200$ & $1.41(1.18-1.68)$ & $1.37(1.14-1.64)$ & $1.30(1.08-1.57)$ \\
\hline$>200$ & $2.29(1.88-2.79)$ & $2.12(1.73-2.60)$ & $1.91(1.54-2.38)$ \\
\hline$p$ value for trend & $<0.0001$ & $<0.0001$ & $<0.0001$ \\
\hline \multicolumn{4}{|l|}{ Serum creatinine $(\mathrm{mol} / \mathrm{l})$} \\
\hline$<80$ & 1.00 & & \\
\hline $80-87$ & $0.98(0.73-1.31)$ & & \\
\hline $88-103$ & $1.03(0.84-1.27)$ & & \\
\hline$>103$ & $1.23(0.99-1.53)$ & & \\
\hline$p$ value for trend & 0.07 & & \\
\hline \multicolumn{4}{|l|}{ Cardiovascular mortality } \\
\hline \multicolumn{4}{|l|}{$\mathrm{eGFR}\left(\mathrm{ml} \mathrm{m^{-1 }} 1.73 \mathrm{~m}^{-2}\right)$} \\
\hline For every $\mathrm{ml} \mathrm{min}^{-1} 1.73 \mathrm{~m}^{-2}$ & $1.32(1.14-1.53)$ & $1.21(1.05-1.40)$ & $1.09(0.93-1.27)$ \\
\hline$\geq 60$ (with chronic kidney disease) & 1.00 & 1.00 & 1.00 \\
\hline$<60$ (without chronic kidney disease) & $1.39(1.10-1.76)$ & $1.29(1.01-1.64)$ & $1.18(0.92-1.52)$ \\
\hline \multicolumn{4}{|l|}{ Further classification } \\
\hline$\geq 90$ & 1.00 & 1.00 & 1.00 \\
\hline $60-89$ & $0.77(0.46-1.29)$ & $0.71(0.42-1.20)$ & $0.65(0.39-1.11)$ \\
\hline $45-59$ & $0.96(0.55-1.67)$ & $0.86(0.50-1.50)$ & $0.79(0.45-1.39)$ \\
\hline $30-44$ & $1.19(0.65-2.17)$ & $0.94(0.51-1.73)$ & $0.67(0.35-1.27)$ \\
\hline $15-29$ & $4.64(2.15-10.01)$ & $2.90(1.31-6.46)$ & $2.03(0.85-4.85)$ \\
\hline$p$ value for trend & $<0.0001$ & 0.01 & 0.27 \\
\hline \multicolumn{4}{|l|}{$\operatorname{AER}(\mu \mathrm{g} / \mathrm{min})$} \\
\hline$<20$ & & 1.00 & 1.00 \\
\hline $20-200$ & $1.18(0.90-1.54)$ & $1.12(0.86-1.47)$ & $1.06(0.80-1.40)$ \\
\hline$>200$ & $2.73(2.10-3.57)$ & $2.46(1.87-3.24)$ & $2.00(1.48-2.71)$ \\
\hline$p$ value for trend & $<0.0001$ & $<0.0001$ & $<0.0001$ \\
\hline \multicolumn{4}{|l|}{ Serum creatinine $(\mathrm{mol} / \mathrm{l})$} \\
\hline$<80$ & 1.00 & & \\
\hline $80-87$ & $0.94(0.61-1.45)$ & & \\
\hline $88-103$ & $1.03(0.76-1.38)$ & & \\
\hline$>103$ & $1.05(1.08-1.98)$ & & \\
\hline$p$ value for trend & 0.02 & & \\
\hline
\end{tabular}

${ }^{a}$ Adjusted for age and sex

${ }^{\mathrm{b}}$ Adjusted for age, sex, and AER

${ }^{\mathrm{c}}$ Adjusted for age, sex, AER, hypertension, apoB/apoA1, smoking, $\mathrm{HbA}_{1 \mathrm{c}}$ and fibrinogen

Hospital Service showed increasing mortality rates with decreasing eGFR, but no multivariate analyses were reported, so that the results may have been due merely to the confounding effects of age and associated risk factors
[19]. The second study, performed at the Steno Diabetes Center on 227 macroalbuminuric persons, showed that eGFR $<60 \mathrm{ml} \mathrm{min}^{-1} 1.73 \mathrm{~m}^{-2}$ was not a risk factor for allcause mortality, whereas GFR measured by plasma clear- 
Table 4 HRs of all-cause and cardiovascular mortality, adjusted for age and sex and stratified by AER categories, in people with type 2 diabetes in the Casale Monferrato Study

\begin{tabular}{|c|c|c|c|}
\hline & $\begin{array}{l}\text { Normoalbuminuria } \\
(n=754)\end{array}$ & $\begin{array}{l}\text { Microalbuminuria } \\
(n=477)\end{array}$ & $\begin{array}{l}\text { Macroalbuminuria } \\
(n=257)\end{array}$ \\
\hline \multicolumn{4}{|l|}{ All-cause mortality } \\
\hline \multicolumn{4}{|l|}{ eGFR (ml min $\left.{ }^{-1} 1.73 \mathrm{~m}^{-2}\right)$} \\
\hline For every $\mathrm{ml} \mathrm{min}^{-1} 1.73 \mathrm{~m}^{-2}$ & $0.90(0.73-1.10)$ & $1.14(0.95-1.35)$ & $1.42(1.20-1.69)$ \\
\hline$\geq 60$ (with chronic kidney disease) & 1.00 & 1.00 & 1.00 \\
\hline$<60$ (without chronic kidney disease) & $0.86(0.65-1.15)$ & $1.40(1.05-1.87)$ & $1.79(1.28-2.50)$ \\
\hline \multicolumn{4}{|l|}{ Further classification } \\
\hline$\geq 90$ & 1.00 & 1.00 & 1.00 \\
\hline $60-89$ & $0.91(0.53-1.54)$ & $0.55(0.31-0.98)$ & $0.70(0.29-1.67)$ \\
\hline $45-59$ & $0.79(0.44-1.43)$ & $0.85(0.46-1.57)$ & $1.12(0.46-2.77)$ \\
\hline $30-44$ & $0.75(0.35-1.61)$ & $0.55(0.27-1.14)$ & $1.23(0.48-3.13)$ \\
\hline $15-29$ & - & $1.96(0.78-4.94)$ & $3.24(1.15-9.18)$ \\
\hline$p$ value for trend & 0.29 & 0.15 & $<0.0001$ \\
\hline \multicolumn{4}{|l|}{$\begin{array}{l}\text { Cardiovascular mortality } \\
\text { eGFR }\left(\mathrm{ml} \mathrm{min} \min ^{-1} 1.73 \mathrm{~m}^{-2}\right)\end{array}$} \\
\hline For every $\mathrm{ml} \mathrm{min}-1.73 \mathrm{~m}^{-2}$ & $0.90(0.67-1.19)$ & $1.20(0.93-1.57)$ & $1.45(1.16-1.82)$ \\
\hline$\geq 60$ (with chronic kidney disease) & 1.00 & 1.00 & 1.00 \\
\hline$<60$ (without chronic kidney disease) & $0.91(0.61-1.35)$ & $1.41(0.91-2.21)$ & $1.81(1.17-2.82)$ \\
\hline \multicolumn{4}{|l|}{ Further classification } \\
\hline$\geq 90$ & 1.00 & 1.00 & 1.00 \\
\hline $60-89$ & $0.74(0.35-1.58)$ & $0.50(0.20-1.25)$ & $0.67(0.20-2.26)$ \\
\hline $45-59$ & $0.69(0.30-1.58)$ & $0.73(0.28-1.93)$ & $1.08(0.30-3.80)$ \\
\hline $30-44$ & $0.63(0.21-1.83)$ & $0.62(0.21-1.85)$ & $1.18(0.32-4.34)$ \\
\hline $15-29$ & - & $2.32(0.59-9.09)$ & $3.41(0.83-14.09)$ \\
\hline$p$ value for trend & 0.45 & 0.16 & 0.001 \\
\hline
\end{tabular}

ance of ${ }^{51} \mathrm{Cr}$-EDTA was associated with mortality in univariate analysis only [20]. Our analyses, based on more than 10,000 person-years at risk and 670 deaths, expand previous knowledge on this issue, showing that chronic kidney disease, defined as eGFR $<60 \mathrm{ml} \mathrm{m^{-1 }} 1.73 \mathrm{~m}^{-2}$, increases both all-cause (by 23\%) and cardiovascular (by $16 \%)$ mortality, independently of cardiovascular risk factors and AER. This effect is mediated through the effect of macroalbuminuria. Indeed, a significant increasing trend in mortality risk with decreasing eGFR was evident only in macroalbuminuric people. Our findings, therefore, have clinical implications, providing evidence that estimating GFR has no advantage over measuring AER, which is the main independent predictor of 11-year cardiovascular mortality in people with diabetes [13]. As our results are based on eGFR, however, future studies are needed to assess both the usefulness and the feasibility in the clinical setting of measuring rather than estimating GFR to provide better prediction of individual risk.

In our study, the prevalence of chronic kidney disease, defined as eGFR $<60 \mathrm{ml} \mathrm{min}^{-1} 1.73 \mathrm{~m}^{-2}$, was high even in the subgroup of 754 normoalbuminuric people examined, of whom one in three had reduced renal function. This finding is consistent with other studies, suggesting either the involvement of other causes in the prevalence of kidney disease or a reduction in albuminuria resulting from the use of antihypertensive drugs in people with diabetic nephropathy [19-24]. We found that knowledge of eGFR, however, provided no predictive information on long-term mortality in normoalbuminuric people, because eGFR values that defined chronic kidney disease provided no increased risk with respect to eGFR $>60 \mathrm{ml} \mathrm{min}^{-1} 1.73 \mathrm{~m}^{-2}$. Our analyses therefore suggest that the MDRD study equation is not well suited to the purpose of early identification of kidney disease in normoalbuminuric patients $[22,23]$. Whereas this finding is due to the low accuracy of eGFR with regard to real GFR in people with diabetes or to their peculiarity with regard to the general population is currently unknown. In micro- and macroalbuminuric persons with diabetes, low accuracy of eGFR compared with GFR measured by the plasma clearance of ${ }^{51} \mathrm{Cr}$-EDTA has recently been shown [20], whereas data in normoalbuminuric people with diabetes are lacking. Moreover, no long-term follow-up study has assessed the predictive value of eGFR in normoalbuminuric people with diabetes. It is likely that the lack of accuracy of eGFR with regard to measured GFR 
has resulted in a downward bias of estimates of risk both in previous studies and in ours $[19,20]$. Therefore, consistently with others, our findings further emphasise the need for other methods, allowing greater accuracy in measuring GFR than formulas based on creatinine levels, to be implemented in diabetic populations [9].

The MDRD study equation has not yet been validated in people aged $>70$ years. Our cohort included mainly elderly people, and thus it is possible that the predictive value of eGFR could be higher in middle-aged people. Elderly people are characterised by a reduced muscle mass, so that eGFR in these persons is often overestimated. This finding probably accounts for our observation of a J-shaped curve describing the increased risk of mortality among people with the highest levels of eGFR, and is consistent with a study conducted on more than 4,000 elderly persons, 716 of whom had diabetes [25].

Limitations of our study should be taken into account. Although our analysis was based on 670 deaths in more than 10,000 person-years of observations, the low number of events in each eGFR stratum reduced the power of our study, leading to wide confidence intervals of the HRs, particularly in normoalbuminuric people. The largest proportion of people with diabetes in our cohort had eGFR $>30 \mathrm{ml} \mathrm{min}{ }^{-1} 1.73 \mathrm{~m}^{-2}$; thus, our findings refer mainly to these people. We employed the MDRD study equation without recalibration of the serum creatinine assay to the assay used in that laboratory; thus, a systematic error could have been introduced into the calculation of the GFR estimate used in our study. This error would be greater at low serum creatinine values, leading to less precise GFR estimates at higher values $\left(>60 \mathrm{ml} \mathrm{min} \mathrm{mi}^{-1} 1.73 \mathrm{~m}^{-2}\right)$, whereas at lower levels of GFR calibration errors would be less likely to have a significant impact on the estimated level of GFR and on the stage of kidney disease [9]. At present, however, no international standard for plasma creatinine measurement is available, so our results reflect common clinical practice [9]. As one overnight urine collection was collected at baseline, misclassification of albuminuria categories might have biased our results downwards. The strengths of the study are the representativeness of the study base with regard to the Italian diabetic population, the high estimated completeness of ascertainment, the centralised assessment of measurements and the recruitment of persons cared for both by general practitioners and diabetes clinics, thus limiting the effect of selection bias on our results. Finally, even if the results of our study suggest a limited clinical usefulness of eGFR in predicting cardiovascular disease in patients with diabetes, eGFR maintains its clinical usefulness, more than creatinine alone, when used for drug selection or for adjusting drug doses.

In conclusion, our population-based study suggests that macroalbuminuria is the main predictor of mortality, independently of both eGFR and cardiovascular risk factors, whereas eGFR provides no further predictive information in normoalbuminuric people.

Acknowledgements We thank the patients, the nurses at the diabetes clinic, the diabetologists and the general practitioners for long-standing collaboration in this study. The Casale Monferrato Study is supported by grants from the Piedmont region. We also acknowledge the contribution of the Italian Association for Cancer Research and the Compagnia San Paolo/FIRMS.

Conflict of interest statement The authors have no conflict of interest with regard to this study.

\section{References}

1. Anavekar NS, McMurray JJ, Velazquez EJ et al (2004) Relation between renal dysfunction and cardiovascular outcomes after myocardial infarction. N Engl J Med 351:1285-1295

2. Verhave JC, Hillege HL, Burgerhof JG, Gansevoort RT, de Zeeuw D, de Jong PE; PREVEND Study Group (2005) The association between atherosclerotic risk factors and renal function in the general population. Kidney Int 67:1967-1973

3. de Zeeuw D (2005) Albuminuria, just a marker for cardiovascular disease, or is it more? J Am Soc Nephrol 16:1883-1885

4. Go AS, Chertow GM, Fan D, McCulloch CE, Hsu CY (2004) Chronic kidney disease and the risks of death, cardiovascular events, and hospitalization. N Engl J Med 351:1296-1305

5. Hostetter TH (2004) Chronic kidney disease predicts cardiovascular disease. N Engl J Med 351:1344-1346

6. Schiele F, Legalery P, Didier K et al (2006) Impact of renal dysfunction on 1-year mortality after acute myocardial infarction. Am Heart J 151:661-667

7. Cooper WA, O'Brien SM, Thourani VH et al (2006) Impact of renal dysfunction on outcomes of coronary artery bypass surgery: results from the Society of Thoracic Surgeons National Adult Cardiac Database. Circulation 113:1063-1070

8. American Diabetes Association (2006) Standards of medical care in diabetes-2006. Diabetes Care 29:S4-S42

9. Lamb EJ, Tomson CR, Roderick PJ (2005) Clinical Sciences Reviews Committee of the Association for Clinical Biochemistry. Estimating kidney function in adults using formulae. Ann Clin Biochem 42:321-345

10. Levey AS, Bosch JP, Lewis JB, Greene T, Rogers N, Roth D (1999) A more accurate method to estimate glomerular filtration rate from serum creatinine: a new prediction equation: Modification of Diet in Renal Disease Study Group. Ann Intern Med 130:461-470

11. Bruno G, Cavallo-Perin P, Bargero G et al (1996) Prevalence and risk factors for micro- and macroalbuminuria in an Italian population-based cohort of non-insulin-dependent diabetic subjects. Diabetes Care 19:43-47

12. Bruno G, Biggeri A, Merletti F et al (2003) Low incidence of endstage renal disease and chronic kidney disease in type 2 diabetes: a 10-years prospective study. Diabetes Care 26:2353-2358

13. Bruno G, Merletti F, Biggeri A et al (2005) Fibrinogen and albumin excretion rate are major independent predictors of 11years cardiovascular mortality in type 2 diabetes: the Casale Monferrato study. Diabetologia 48:427-434

14. Bruno G, Cavallo-Perin P, Bargero G, Borra M, D'Errico N, Pagano G (1996) The associations of fibrinogen with glycemic 
control and albumin excretion rate in patients with non-insulindependent diabetes. Ann Intern Med 125:653-657

15. Bruno G, LaPorte R, Merletti F, Biggeri A, McCarty D, Pagano G (1994) National diabetes programmes: application of capturerecapture to 'count' diabetes? Diabetes Care 17:548-556

16. Garancini MP (1996) L'epidemiologia del diabete non-insulinodipendente e della ridotta tolleranza al glucosio. In: Vaccaro $\mathrm{O}$, Bonora E, Bruno G, Garancini MP, Muntoni S (eds) Società Italiana di Diabetologia, Gruppo di Studio Epidemiologia e Statistica, Il Diabete in Italia. Kurtis, Milan, pp 17-30

17. Bruno G, Merletti F, Biggeri A et al (2003) Progression to overt nephropathy in type 2 diabetes: the Casale Monferrato study. Diabetes Care 26:2150-2155

18. Rossing P (2006) Prediction, progression and prevention of diabetic nephropathy. The Minkowski Lecture 2005. Diabetologia 49:11-19

19. Patel UD, Young EW, Ojo AO, Hayward RA (2005) CKD progression and mortality among older patients with diabetes. Am J Kidney Dis 46:406-414
20. Rossing P, Rossing K, Gaede P, Pedersen O, Parving HH (2006) Monitoring kidney function in type 2 diabetic patients with incipient and overt diabetic nephropathy. Diabetes Care 29:1024-1030

21. Kong AP, So WY, Szeto CC et al (2006) Assessment of glomerular filtration rate in addition to albuminuria is important in managing type II diabetes. Kidney Int 69:383-387

22. MacIsaac RJ, Tsalamandris C, Panagiotopoulos S, Smith TJ, McNeil KJ, Jerums G (2004) Nonalbuminuric renal insufficiency in type 2 diabetes. Diabetes Care 27:195-200

23. MacIsaac RJ, Panagiotopoulos S, McNeil KJ et al (2006) Is nonalbuminuric renal insufficiency in type 2 diabetes related to an increase in intrarenal vascular disease? Diabetes Care 29:1560-1566

24. Parving HH, Lewis JB, Ravid M, Remuzzi G, Hunsicker LG; DEMAND investigators (2006) Prevalence and risk factors for microalbuminuria in a referred cohort of type II diabetic patients: a global perspective. Kidney Int 69:2057-2063

25. Shlipak MG, Sarnak MJ, Katz R et al (2005) Cystatin C and the risk of death and cardiovascular events among elderly persons. N Engl J Med 352:2049-2060 